\title{
China English, Not a Legitimate Variety of English
}

\author{
Feng Minghui ${ }^{1, ~ *, ~ H u o ~ D o n g m i n g ~}{ }^{2}$ \\ ${ }^{1}$ School of International Education, Anhui Polytechnic University, Wuhu, China \\ ${ }^{2}$ College of Electrical Engineering, Anhui Polytechnic University, Wuhu, China
}

\section{Email address:}

mingh_feng@163.com (Feng Minghui)

${ }^{*}$ Corresponding author

\section{To cite this article:}

Feng Minghui, Huo Dongming. China English, Not a Legitimate Variety of English. International Journal of Education, Culture and Society. Vol. 6, No. 2, 2021, pp. 48-53. doi: 10.11648/j.ijecs.20210602.12

Received: March 19, 2021; Accepted: March 31, 2021; Published: April 12, 2021

\begin{abstract}
China has a long history in its contact with English. With the increasingly influence of China expands in the worldwide stage, 'China English' has emerged correspondingly to satisfy her need to communicate its stories to the audiences around the world. And the situation has developed to the extent that some scholars and English learners are so confident in 'China English' as to conclude that it is a member of the 'World Englishes', varieties of English that developed in other parts of the globe outside native English-speaking countries. This conclusion goes too far when it is testified against different factors both at home and abroad. This article firstly introduces the background of the proposal of the concept "China English", and then discusses the validity of the concept against Butler's criteria, what standard English is from the Chinese English learners' eye, the situation of China English in China, other elements preventing the popularity of China English, and in the end, by referring to relevant figures, the authors point out that standard English is a necessity for Chinese English learners and it is suggested that Standard English, instead of China English, still has its place in English teaching and learning in China.
\end{abstract}

Keywords: China English, Standard English, Butler's Criteria, Interference from Chinese Language, Government Policy

\section{Introduction}

The concept of 'China English' has been put forward for decades and essays [4] about this issue can be easily found at home and abroad. A number of related essays [5, 8, 9-11, 13] share the similar point of view that China English is a developing and expanding variety of English. However, I doubt the actual acceptance of 'China English' and am not optimistic about it becoming a member of the world Englishes at present.

China English first appeared when Ge shared his viewpoint on translation from Chinese to English [10]. Ge thought that since every nation has its unique culture that cannot always find its equivalents in other languages, it is inevitable that China English would take place, such as 'Four Books', which cannot be classified as Chinglish. Since then, the concept 'China English' has been highly discussed in various publications $[9,10,13]$. But the concept Ge talked about is not in any sense a variety of English. According to Ge, China English has two features: Chinese specific items expressed in English; being difficult for English speakers to understand, but can be understood through explanations. Then there comes the question: if China English, a strategy used in translation, serves only as a tool to facilitate the communication between different cultures, will it become a nativized variety in China?

In this essay, it firstly evaluates China English against Butler's five criteria [8] to see to what degree China English has developed. Then it discusses China English's popularity in mainland China, including the actual usage of it and its acceptability among Chinese English learners. In the next part, it lists other factors that exert influence on the real existence of China English. And then based on what have been discussed, it argues that there is a lack of solid foundation or favorable environment for the completely national and international recognition of China English. And following that it suggests that Standard English is necessary both for Chinese English learners and international communication at the moment. In the final part, it calls for rational attitude toward China English and the necessity to teach and learn Standard English. 


\section{Standard English in the Eye of Chinese English Learners}

As the term 'Standard English' will be frequently referred to in the following part of this essay, there is a need for the authors to give some explanation about it here. Standard English has been in debate for years and not yet a fixed concept at present. And for this essay, it is not the main point of our discussion, therefore we just define it briefly in the perspective of Chinese English learners.

As the global lingua franca, English is undoubtedly popular worldwide. There is continuing debate over Standard English in the context of globalization, and British English and American English have been the two dominant models as Standard English for English teaching and learning in a large number of EFL countries. As for China, it has been going through English Boom since the Reform and Opening up. And British English and American English are regarded as 'perfect' English by most Chinese English learners who are proud of speaking in a British or American accent. This phenomenon is attributed to the United Kingdom's rich culture and Unites States' developed economy and technology, which exert great influence on Chinese teenagers, with Shakespeare, Christmas, Hollywood movies, Oxford University and Harvard University, etc. known to all. For college and university students, VOA and BBC are the two major Apps for them to practice English listening, and these two countries are the top two preferable destinations to pursue further education abroad, recommended by their English teachers who may also get British or American degrees. Therefore, in this essay, when the authors mention Standard English, it is deemed as equivalent of British English and American English.

\section{China English Against Butler's Criteria}

Butler's five criteria are frequently referred to when a variety of English is discussed. Butler holds that a legitimate variety of English generally goes through five stages and each stage has its characteristics [8]. And these five standards are the way to measure if a variety of English really exists. Bolton [1] argues that many established varieties of English fail the fifth criterion. In the case of China English, it is safe to say that it falls down against the last two criteria. As to whether the first three are fully fulfilled, I adventure to say it is not.

For the first criterion of pronunciation, many researchers think China English fulfills it, arguing that Chinese English learners tend to pronounce $[ð],[\theta]$ as $[\mathrm{z}]$, [s] respectively, cannot tell the differences between long vowels and short vowels, such as [i] and [i:], are inclined to add [ə] when words end with plosives, etc. This is indeed the case. But the author incline to classify these phenomena as barriers caused by different language systems on the way to Standard English accent. In fact, the language environment in mainland China is quite complicated as it covers a vast territory which is home to
56 ethnic groups. Each group has its unique language. And even in the Han nationality, China's main ethnic group, there is huge difference in pronunciation among different dialects, thus, correspondingly, discordant English pronunciation in different regions. Therefore, it is not an easy task to form a uniform English pronunciation that can be handed down from generation to generation.

As for the second criterion of peculiar words and phrases, China English is outstanding in this term. More than 3500 words with Chinese characteristics are included in the Oxford English Dictionary online, such as 'goji', 'guanxi', 'fengshui', 'Putonghua', 'open-door policy', 'iron rice bowl', 'one country two systems', etc. Just name a few. Based on these words and phrases, some researchers $[5,6,9,10,13]$ contend that China English has been well accepted by native English speakers and falls into Butler's second criterion. However, on the contrary, we tend to think that these specific Chinese words and phrases are understood by native speakers and assimilated into the English language. These Chinese-style translated words and phrases are accepted by the English world in order to have a good understanding of Chinese specific culture, and these translations then become authentic English words and phrases with time, not peculiar expressions of China English anymore. This is quite common when two different cultures collide. Have a look at the origin and development of the English language itself, which is inclusive enough as to absorb various linguistic elements from other languages, such as Latin (vice versa, etc., alma mater, per se), French (buffet, gourmet, café, genre, Renaissance), German (hamburger, fest, kindergarten, noodle), etc. English is such a fluid language that it takes into new expressions to enrich itself, which in turn contributes its popularity around the world. Hence, in the case of Chinese words and phrases, there is of no exception. They are just part of these linguistic elements that facilitate the developing of this growing language, being absorbed by it and become an integrated part of it in the end. Just as we cannot term 'hamburger', 'kindergarten', 'noodle' as German English words, similarly, the words 'typhoon', 'fengshui', 'shanghai' are just English words that are borrowed from China, of which there is nothing to be proud. These words are just witnesses of cultural interactions, a common phenomenon between cultures, far from being peculiar words and phrases of a nativized variety of English.

When it comes to the third criterion, the history of English in China is long. During the early 17 th century, the contact between China and English-speaking countries generated the Chinese Pidgin English, which finally took shape in the 18th century [14], and it disappeared after English is formally taught in schools. Then Chinglish, Chinese English, Chinese-style English. And now the heated debate on China English. English Boom has been a phenomenon since the late 1970s. Till now, systematical learning of English in mainland China has lasted for more than 180 years. However, long time of English learning does not help form a Chinese community where English is the dominant language used by people living in the community. In China, Putonghua is the language to bridge smooth communication when people from different 
areas come together to do business, receive education. Compared with established English varieties, such as Indian English, the influence of English in China is limited, to which different historical backgrounds and domestic situations contribute. In India, as people from the southern part and these from the northern part cannot share one uniform domestic language for communication in history, English is chosen as a national language to perform the task and becomes the official language in this country, widely used in education, business, politics, literature, etc. Indian English with a history of more than 400 years, has formed a community where English is used by its speakers to communicate, while China English is far from being a variety commonly used in the Chinese society.

After analyzing China English against Butler's first three criteria, it is full of skepticism about the legitimate existence of China English.

\section{China English at Home}

Looking at the developing history of established English varieties, it can be seen that a local variety should be accepted and widely used by its people at home for a long period till it becomes a recognizable language in the speech community. Hence, if China English wants to be a member of world Englishes, it has to go through the similar process. It should firstly be widely accepted and used in China.

\subsection{China English's Acceptance Among Chinese English Learners}

Both surveys carried out at home and abroad have suggested that most of Chinese English learners in colleges and universities are in favor of learning Standard English and American English accent is much more preferred [8, 15]. They do not want people to tell they are Chinese when speaking English and are happy when their spoken English is recognized by native speakers. When we look at the statistics about Chinese people's favorite destinations for travel or further education, it turns out that United Kingdom and United States are the top two choices [2]. Therefore, it is natural for them to be inclined to master Standard English. In fact, most English learners interviewed realize the existence of English varieties, but few of them are willing to learn them nor do they think China English will appear as a member of world Englishes in the future. This is influenced by the general atmosphere, mainly the official policy and the school's teaching mode. As an English major myself, during my college years, American English was popular among students because we were taught and encouraged by our English teachers, who themselves think highly of American English, to try to speak fluent American English. They would always correct us immediately if the pronunciation was not produced in an American way. The situation is still the same today in colleges and universities.

In addition, most people learn English alongside their different purposes, some to travel or study abroad, others to communicate with native speakers without barriers or for the convenience to read foreign literature smoothly. And the use of English among Chinese speakers is limited to quite a few fields, of which education is of a high proportion. The situation in the education circle is that, leaders of school administrative apartments and reputed professors, who are influential representatives in the area of education, mostly receive their master degrees or doctorial degrees in developed English countries, most in America, because of its prestigious universities, good education and leading scientific researches. Then it is natural for them to take American English or British English as Standard English for granted. The question is: if powerful people in the education circle value Standard English far above other varieties of English, on which does China English's foundation lie domestically? Let alone be internationally recognized as a variety of English.

\subsection{The Number of Chinese People Who Are Actually Using English}

Essays [8, 11] published believe that China English falls into the second phase, an expanding variety, of Kachru's three phases of the development of non-native varieties of English [7], and argue that it will come to the third phase, and will be accepted as a member of world Englishes in the future. However, these researchers are similar in that, they come to their conclusions by equaling the number of Chinese English learners and the long history of English learning in mainland China to the degree to which the language is actually used. They mistake the quantity for the quality, which leads to their bold prediction for China English. They are so optimistic as to excessively overestimate the actual usage of English in China.

It is true that there has been English Boom since the reform and opening-up policy in 1978, a fact frequently quoted to illustrate the rapid development of China English. But when we have a close look at this phenomenon, a different conclusion can be drawn. There indeed are over 400 million English learners in mainland China today [3], but the fact is that most of these learners just learn some simple English words, such as greeting words 'hello', 'good morning', 'how do you do', etc., and people seldom use English in their daily routine. As a matter of fact, the number of people who actually use English pales when compared with the total number of English learners, the proportion being only seven percent in the national 2000 survey [3]. And these seven percent users are mainly confined in the regions of education, business and media. When we take the field of education as an example, it can be found that English is majorly learned and used as a tool to pass the domestic English examinations (such as College English Text 4, CET6, Text for English Major 4, TEM8), to go abroad to attend the international classes, and to publish English essays in English journals, etc. The number of professors with $\mathrm{PhD}$ degrees teaching in China's colleges and universities, who are able to publish high-level papers in English-language journals but cannot use or seldomly use it in daily communication, is not yet known. It is a quite common situation as far as we know.

Therefore, only a limited number of people are able to use English in China, and the language basically functions as a 
tool, a foreign language, not the same as it is in India, Pakistan, Singapore, where nativized English acts as the second language or the official language being used in various walks of life throughout the nation. In China, English is just a performance variety, instead of an institutionalized variety, serving as a bridge for the benefit of international exchanges [12]. The odds of China English developing into a variety of English is unduly overestimated.

\section{Other Factors Influencing the Popularity of China English}

Apart from lukewarm attitudes of Chinese English learners toward China English and a low percentage of actual English users, negative transfer from Chinese to English, which would inevitably cause difficulty in communication with native speakers, can have impact on the developing of China English. Also, policymakers have a role to play through producing language teaching syllabus at different levels of schools.

\subsection{China English with Interference from the Chinese Language}

Wang [13] and Li [9] considered China English has already existed and gave their definitions. According to these two professors, China English has two major features: based on Standard English; with Chinese characteristics. They then explained that every language bears the specific features of its culture. Therefore, when Chinese people speak English, write in English, the 'English' would unavoidably carry the characteristics of Chinese culture and thinking patterns, but without interference as that in Chinglish. As a matter of fact, both China English and Chinglish are inevitably influenced by the Chinese mother tongue with specific Chinese characters. And according to Odin's transfer theory, these characteristics can facilitate or hinder the understanding of the 'English'. The difference between the two is to what degree they are negatively influenced. It is much proper to say that China English is more understandable than Chinglish to native speakers, but it also bears Chinese negative influence.

Actually, due to different language systems and thinking patterns, Chinese English learners suffer from the interference of Chinese in English learning, phonologically, lexically as well as grammatically. And the lower level a learner is at in English learning, the stronger the interference. Here, the 'interference' does not refer to superficial grammatical mistakes in Chinglish, but the negative influences exerted by language usage habits and way of thinking. For example, the word 'propaganda' is used in English in a derogatory sense, while for Chinese learners it means the same with 'publicity'. More examples, 'landlord', 'ambition', 'peasant' etc., all these words are treated in a Chinese way with different meanings from the original ones because of different social and cultural context. These words with Chinese characteristics can lead to nothing but misunderstanding in intercultural communication. China English with these words will not be embraced by native speakers, at least not at present.
Some may argue that there is the similar situation in other varieties of English. For example, in Indian English, there are expressions with specific Indian features that means differently from what they originally are in Standard English, such as 'shut up', 'uncle', 'aunty'. And this does not prevent Indian English from becoming an established English variety. However, we cannot ignore the fact that in Indian English is the official language at home and abroad, which provides it the chance to introduce itself to the native speakers. While, for China, the standard Chinese language or Putonghua owns the superior status over English.

\subsection{Government Policy on English Learning}

Government plays an important role in deciding what language should be nationally promoted in the country and it is the maker of language policies. The Chinese government attaches importance to standard Chinese language or Putonghua, which can be told from the government's language policy domestically and internationally. In mainland China, English has no priority when compared with Putonghua, as 57\% of the Chinese population are capable of communicating with Putonghua, while only seven percent use English often [3]. In recent years, the importance of English examination in gaokao or College Entrance Examination has been reduced, and from 2019 the English examination can be taken twice in gaokao in the new policy to help release the pressure of learning English for Chinese students. Some educationalists and officials applaud the reduction of the importance of English, considering that too much emphasis on English can do harm to the Chinese culture, language and individual identity. The promotion of Chinese over English by the government is the same in the global scope. The Chinese government has been working at the promotion of Chinese language and culture learning worldwide, by sending out Chinese teachers overseas and setting up Confucius Institutes, as a strategy to increase its influence in the world as well as satisfy native English speakers' need to master Chinese to seek business opportunities in the increasingly growing Chinese markets.

In mainland China, English is treated as a foreign language, which is usually learnt in the form of formal school teaching. And this distinguish it from other established English varieties, for the latter gain an official language position and are learnt in a casual way in daily life, not as formal as China's school teaching. Moreover, in contrast with countries with established English varieties, Standard English is highly promoted by the Chinese officials in English teaching and learning. The government hope its talents can master the Standard English to increase its impact on influential English-speaking world in terms of scientific research, business and commerce, and future competitions. The typical 'Top-down' policy implementation mode in China results in that Standard English is taught in all classrooms (at least the goal is Standard English, ignoring the quality of the teachers and the conditions of teaching), from elementary school, middle school, throughout universities. Other English varieties are not or far less encouraged among Chinese English learners, let alone the China English, whose existence 
is still in debate. The guiding function of the Chinese government's policy determines that neither Standard English nor China English would become a second language in this country with Putonghua being the nationally used language, and that China English is not and will not be promoted by officials and thus not being embraced by the majority of Chinese English learners.

\section{Standard English, Still a Necessity for Chinese English Learners}

In one of his essays, Kirkpatrick [8] puts forward the thought-provoking question that 'Why are the Chinese learning English?' Then he supposes that in many Asian countries, the most important role of English is to communicate with other non-native speakers in the region. Therefore, the learning of Standard English may be not that necessary, because a local variety such as China English will serve the role better. At the end of his essay, he goes further as to predict that China English as a local variety will inevitably take shape and native speakers will need to accommodate to nativized varieties of English in the future as non-native speakers of English in the world outnumbers native speakers at present and the number of non-native speakers continues to grow at a fast rate. This sounds inspiring at first sight, but when related statistics are scrutinized closely, different conclusion can be drawn. Firstly, let us look at the statistics [2] of Chinese students studying abroad:

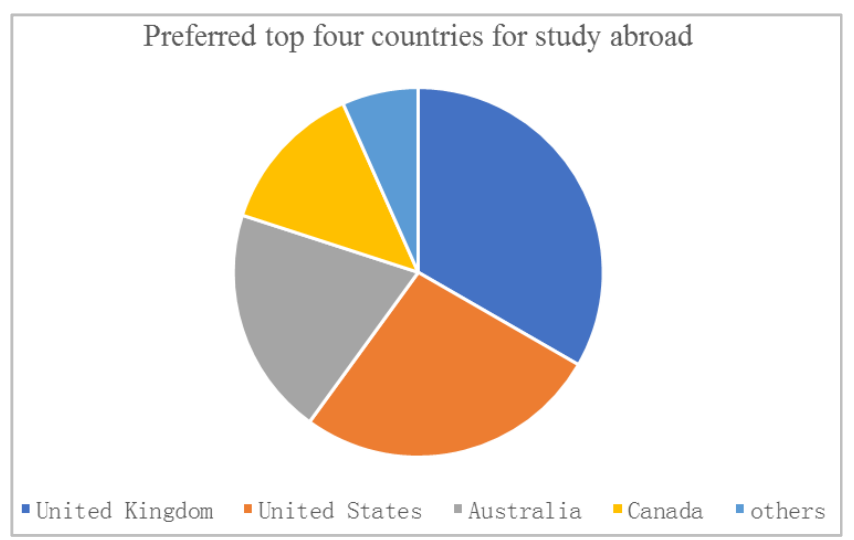

Figure 1. United Kingdom 33\%; United States 27\%; Australia 20\%; Canada $13 \%$; others $7 \%$.

Official data from the Ministry of Education, PRC, show that during the 40 years since opening-up policy, the number of people in mainland China studying abroad has continued to grow and reached 5.1949 million in total. At present, there are 1.4541 million Chinese studying abroad. In the year of 2017 alone, the number of people seeking education abroad is as large as 608,400. And China continues to be the world's largest student source country. Among these numbers, it should be noted that the preferred top four countries for study abroad are United Kingdom, United States, Australia, Canada subsequently. As the pie chart above shows.

Then the statistics of students studying in China:
Statistics demonstrates that Asian and African students take up a major proportion of $76.52 \%$ in students studying in China. The top four source countries are Korea, Thailand, Pakistan, India in sequence.

Figures 2 and 3 do echo the opinion of Kirkpatrick that there exists frequent communication between non-native speakers, but Figure 1 shows that for these Chinese going abroad, there is a need to learn Standard English with UK and US being the top two destinations. Besides, the number of Asian students coming to China for study is about 490,000 in 2018, while that of Chinese studying abroad exceeds 6000,000 in 2017 [2], which means that there is much need to study Standard English than local varieties, considering the factor of the number only.

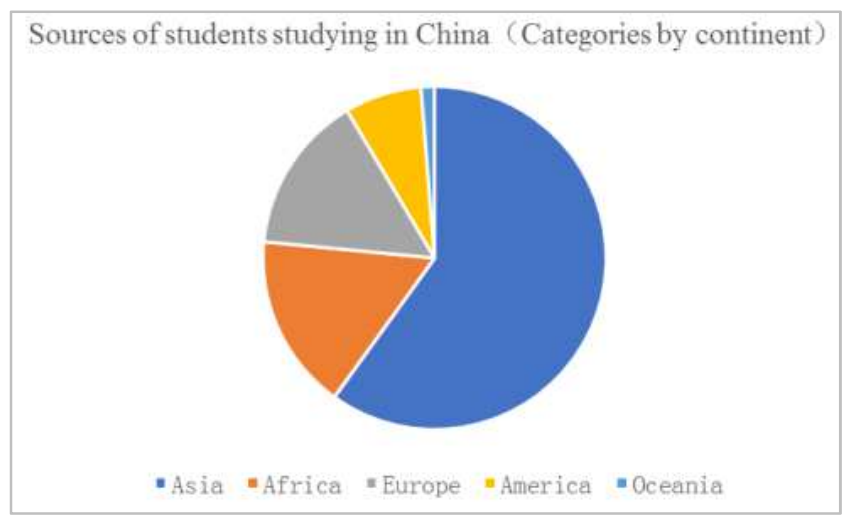

Figure 2. Asia 59.95\%; Africa 16.57\%; Europe 14.96\%; America 7.26\%; Oceania $1.27 \%$

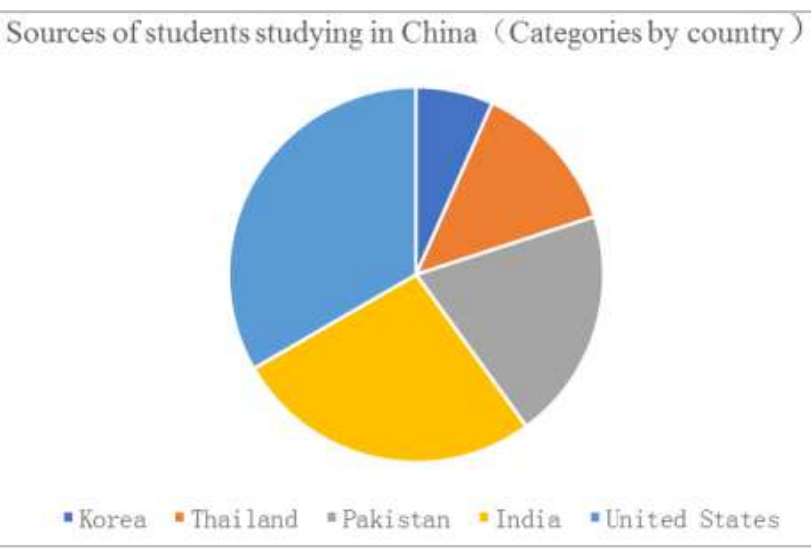

Figure 3. Korea 7\%; Thailand 13\%; Pakistan 20\%; India 27\%; United States $33 \%$.

Kirkpatrick [2] also puts forward communication solutions between non-native speakers' countries: Speakers of Variety X must accommodate to speakers of Variety $\mathrm{Y}$ when in the cultural domains of Variety Y speakers and vice versa. When in 'neural' domains, speakers must accommodate to each other. If so, let us suppose, there are five Asian countries, with each owning their specific English varieties, China English being one of them. That is to say, a Chinese should learn four other local varieties in their cultural domains and then it is the same for the other four countries because all these five countries care no more about the mastery of Standard English. When the 
five countries come together for a meeting, it will be difficult and impractical for them to understand each other. Learning Standard English versus learning four other varieties, which is a better and more efficient solution?

\section{Conclusion}

All above discussed and in consideration of the Chinese learners' attitudes toward English, the government language policy, and China English's status, it is safe to conclude that China English is far from being a legitimate variety of English. It fails to concord with Butler's five criteria. It is not that popular among the Chinese English learners with limited speakers, and heavy with Chinese language influences without much official support.

Also, an objective and sober attitude should be taken toward the study of English without too much optimism and overestimation. China English has not arrived at the place where it can replace the study of Standard English, nor does it gain the equivalent position as an official language as in Singapore, India, Africa. Too much confidence in China English as a variety of English would be destructive for English learning at present, especially for the students, who will suffer for the external examination is set up in accordance with the criteria of Standard English. Therefore, Standard English should still be the proper choice for Chinese English learners. Too much pride in and satisfaction with the 'China English', which means too much emphasis is put on expressing Chinese specific culture in English in our Chinese way of thinking, it will definitely cause misunderstandings in international communication. Consistent efforts should be put to facilitate the mastery of Standard English for the moment.

\section{Acknowledgements}

The work was supported by the Anhui Polytechnic University Research Startup Foundation (2019YQQ007).

\section{References}

[1] Bolton Kingsley (2000) The sociolinguistics of Hong Kong and the space for Hong Kong English. World English, 19 (3).

[2] Beijing Daily. 2019. 'Do you know where Chinese students prefer to study abroad?' Onlineat https://baijiahao.baidu.com/s?id=1627869696911535244andw $\mathrm{fr}=$ spiderandfor=pc (Accessed August 28, 2019).
[3] Bolton, K., and Botha, W. (2015). Researching English in contemporary china. World Englishes, 34 (2), 169-174.

[4] Du Ruiqing and Jiang Yajun (2001). Jin ershi nian 'Zhongguo Yingyu' yanjiu shuiping [An overview of studies of 'China English' in the last two decades]. Waiyu Jiaoxue yu Yanjiu [Foreign languages teaching and research], 33 (1), 37-41.

[5] Jia Guanjie (1997). Wei Zhongguo Yingyu yibian [To defend China English]. Waiyu yu Waiyu Jiaoxue [Foreign languages and foreign language teaching], 5, 11-12.

[6] Jia Guanjie (2013). Zhongguo Yingyu zai yanjiu [Further study on China English]. Dangdai Waiyu Yanjiu [Contemporary foreign language study]. 3 .

[7] Kachru, Braj B. (1992) The other tongue. English Across Cultures. Urbana: University of Illinois Press. (2nd edition).

[8] Kirkpatrick, A., and Zhichang, X. (2002). Chinese pragmatic norms and 'China English'. World Englishes.

[9] Li Wenzhong (1993) Zhongguo Yingyu yu Zhongguoshi Yingyu [China English and Chinese Enlgish]. Waiyu Jiaoxue $y u$ Yanjiu [Foreign languages teaching and research] 4, 18-24.

[10] Lin Qiuyun (1998) Zuowei waiyu de Yingyu bianti: Zhongguo Yingyu [A variety of English as a foreign language: China English] Waiyu yu Waiyu Jiaoxue [Foreign languages and foreign language teaching]. $110(8)$.

[11] Megan Eaves (2011). English, Chinglish or China English? English Today, 27, 64-70.

[12] Sun Li (1989), Yingyu Guobie Bianti de Yanjiu he Yingyu zai Zhongguo [English Varieties and English in China]. Waiguoyu [Foreign Languages]. 2, 21.

[13] Wang Rongpei (1991) Zhongguo Yingyu shi Keguan Cunzai [China English is an objective existence]. Jiefangjun Waiyu Xueyuan Xuebao [Journal of PLA University of Foreign Languages], 1, 1-8.

[14] Wei Yun and Fei Jia (2003). Using English in China. English Today. 4, 42-47.

[15] Xu Hongchen and Gao Yihong (2014). Sici Daxing Guoji Huodong Qianhou Daxuesheng Zhiyuanzhe dui Shijie Yingyu de Taidu [College students' attitude towards world English before and after four major international events] Foreign language Education 35 (1).

\section{Biography}

Feng Minghui (1991--), School of International Education, Anhui Polytechnic University, Wuhu, Anhui, China; research direction: translation, English teaching and learning, world Englishes. 